Article

\title{
Inflammatory Bowel Diseases and Coexisting Spondyloarthritis: A Neglected and too Often Under-Reported Association by Radiologists. A Multicenter Study by Italian Research Group of Imaging in Rheumatology
}

\author{
Maria Antonietta Mazzei ${ }^{1,2}{ }^{D}$, Francesco Gentili ${ }^{3, *}$, Susanna Guerrini ${ }^{3}\left(\mathbb{D}\right.$, Nunzia Di Meglio ${ }^{1}$, \\ Giuseppe Lo $\operatorname{Re}^{4}{ }^{\mathbb{D}}$, Marina Carotti ${ }^{5}$, Francesca Interlicchia ${ }^{6}$, Alfonso Reginelli ${ }^{2,7}$, \\ Antonio Barile 2,8 (D), Giulia Sadotti ${ }^{1}$, Ubaldo Plastina Romeo ${ }^{1}$, Ernesto La Paglia ${ }^{\text {, }}$ \\ Nicola Maggialetti ${ }^{10}$, Rita Lo Scalzo ${ }^{11}$, Alessia Vinci ${ }^{4}$, Giuseppe Capodieci ${ }^{6}$, Giovanna Vacca ${ }^{7}$, \\ Federico Bruno ${ }^{8}$, Luca Cantarini ${ }^{12}$, Bruno Frediani ${ }^{12}$, Antonio Marchesoni ${ }^{13}$ (D), \\ Andrea Giovagnoni ${ }^{5}$, Luca Volterrani ${ }^{1}$ and Luca Brunese ${ }^{2,10}$
}

1 Unit of Diagnostic Imaging, Department of Medical, Surgical and Neuro Sciences, University of Siena, Azienda Ospedaliero-Universitaria Senese, 53100 Siena, Italy; mariaantonietta.mazzei@unisi.it (M.A.M.); dimeglionunzia@gmail.com (N.D.M.); sadotti.giulia@gmail.com (G.S.); ubaldopl@gmail.com (U.P.R.); lucavolterrani@gmail.com (L.V.)

2 Italian Research Group of Imaging in Reumathology, Italian Society of Medical Radiology (SIRM), 20122 Milan, Italy; alfonsoreginelli@hotmail.com (A.R.); antonio.barile@cc.univaq.it (A.B.); lbrunese@sirm.org (L.B.)

3 Unit of Diagnostic Imaging, Department of Radiological Sciences, University of Siena, Azienda Ospedaliero-Universitaria Senese, 53100 Siena, Italy; guerrinisus@gmail.com

4 Department of Medical Biopathology and Biotechnology, AOUP Paolo Giaccone, 90127 Palermo, Italy; giuseppe.lore12@gmail.com (G.L.R.); avinci14@gmail.com (A.V.)

5 Department of Radiology, Ospedali Riuniti, Università Politecnica delle Marche, 60126 Ancona, Italy; marina.carotti@gmail.com (M.C.); agiovagnoni@sirm.org (A.G.)

6 Department of Radiology, ASP Siracusa, UOC Radiologia Ospedale "Umberto I", 96100 Siracusa, Italy; francescasisi@hotmail.it (F.I.); giuseppe.capodieci@libero.it (G.C.)

7 Department of Internal and Experimental Medicine, University of Campania "Luigi Vanvitelli", 81100 Naples, Italy; g.vacca88@gmail.com

8 Department of Biotechnological and Applied Clinical Sciences, University of L'Aquila, 67100 L'Aquila, Italy; federico.bruno.1998@gmail.com

9 Unit of Diagnostic Imaging, Humanitas Cellini, 10153 Torino, Italy; Ernesto.lapaglia@gradenigo.it

10 Department of Medicine and Health Science "V. Tiberio", University of Molise, 86100 Campobasso, Italy; n.maggialetti@gmail.com

11 Department of Diagnostic Imaging, Diagnostic Imaging Unit, Azienda USL Toscana SUD-EST, Ospedali Riuniti della Valdichiana, 53045 Nottola, Italy; rita.loscalzo@uslsudest.toscana.it

12 Research Center of Systemic Autoinflammatory Diseases and Behçet's Disease and Rheumatology-Ophthalmology Collaborative Uveitis Center, Department of Medical Sciences, Surgery and Neurosciences, University of Siena, 53100 Siena, Italy; cantariniluca@hotmail.com (L.C.); bruno.frediani@unisi.it (B.F.)

13 Department of Rheumatology, G Pini Institute, 20122 Milan, Italy; antonio.marchesoni@asst-pini-cto.it

* Correspondence: francescogentili@gmail.com

Received: 10 November 2020; Accepted: 9 December 2020; Published: 15 December 2020

\begin{abstract}
Purpose: The purpose of this study was to evaluate the prevalence and the underreporting rate of sacroiliitis (SI) in a large cohort of patients with biopsy-proved Crohn's disease (CD) who underwent magnetic resonance enterography (MRE) or computed tomography enterography (CTE). Materials and Methods: Patients with CD were recruited from eight Italian health centers in the
\end{abstract}


period from January 2013 to December 2017. Disease activity was recorded according to the CD activity index (CDAI). The scans were read by two blinded readers who defined the presence of SI according to Assessment of SpondyloArthritis International Society (ASAS) classifications and European League Against Rheumatism (EULAR) recommendations. Moreover, SI was scored using a simplified Spondyloarthritis Research Consortium of Canada (SPARCC) scoring system. Results: Interobserver agreement in diagnosing SI on imaging was good $(\mathrm{K}=0.72-0.83)$. SI was diagnosed in 129 (14.4\%, 54 men, 75 women) out of 894 patients; however, sacroiliac joint (SIJ) abnormalities were not mentioned in the radiological reports of 112 patients (86\%). Fifty (38.7\%) out of 129 patients also underwent a subsequent SIJ evaluation through a dedicated MRI protocol to confirm SI. SI was found in a higher percentage of patients with "active" than "inactive" CD (18\% vs. 4\%). Conclusion: This study confirms the feasibility of CTE and MRE for the screening of SI in CD patients; however, it also underlines the remarkable problem concerning the underreporting of this entity in radiological practice.

Keywords: Crohn's disease; sacroiliitis; CT; MRI; CT enterography; MR enterography

\section{Introduction}

Inflammatory bowel disease (IBD) is an idiopathic disease caused by an inappropriate immune response to an unknown antigen (most likely host intestinal microflora) combined with genetic and environmental factors [1]. The two major types of IBD are ulcerative colitis (UC), which is limited to the colonic mucosa, and Crohn's Disease (CD), which can affect any segment of the gastrointestinal tract, from the mouth to the anus, with a transmural involvement of the gut. Patients with IBD are more prone to the development of spondyloarthropathy (SpA) and malignancy [2,3]. SpA refers to a group of inflammatory diseases with similar clinical, radiologic and serologic features, including ankylosing spondylitis (AS), psoriatic arthritis (PsA), reactive arthritis (ReA), undifferentiated SpA and enteropathic or IBD-associated SpA. SpA is characterized by a wide and various joints' involvement, with the hallmark feature represented by inflammation at enthesis, ligament, tendon or capsular insertions. On the basis of the predominant clinical presentation, spondyloarthropathies are divided into axial SpA and peripheral spondyloarthropathies, [4-6]. SpA has been estimated to occur in percentages of IBD patients ranging from $17 \%$ to $39 \%$ by several studies that also confirmed that $\mathrm{SpA}$ is the most frequent extra-intestinal manifestation in patients with IBD [7].

Sacroiliitis (SI) represents the hallmark of SpA and it may be clinically silent or equivocal in physical examination tests at an early stage, giving magnetic resonance imaging (MRI) a pivotal role for diagnosis, especially in non-radiographic axial spondyloarthritis [8-12]. In fact, signs of sacroiliac joint (SIJ) inflammation, such as periarticular SIJ bone marrow edema (BME), soft tissue edema and osteitis, which constitute early findings of SI, can be detected only by MRI, which today represents a reference technique in rheumatology [12-18]. SIJ erosions, which appear later in the disease history, and other structural changes, including fat deposition, subchondral sclerosis, bony bridges and ankylosis, which represent an advanced disease stage, can be diagnosed by both conventional radiographs and computed tomography (CT), the latter having a higher sensitivity and specificity, although CT scan use is limited in young patients for radioprotection reasons [19]. The introduction of biological drugs (like TNF $\alpha$ inhibitor drugs) capable of changing the course of the disease if administered in the early-mid stages has emphasized the need to detect SI in patients with IBD, many of whom can be asymptomatic or show a normal SIJ radiograph [20-22]. Furthermore, when IBD and SpA coexist, the therapeutic strategy should be modulated to take into account the variable manifestations of IBD, in terms of intestinal and extra-intestinal features, and the clinical manifestations of SpA, with particular attention to peripheral enthesitis, dactylitis and anterior uveitis [7,23-25]. Many patients with IBD undergo computed tomography enterography (CTE) and/or magnetic resonance enterography (MRE) 
as a part of their clinical care to evaluate the extent and severity of the disease and the response to treatment or due to suspicion of complications [26-35]. Even if these examinations are not targeted for the evaluation of the SIJ, and MRE in particular is not carried out with the appropriate planes or sequences, SIJ are included in at least two planes (axial and coronal before and after intravenous contrast media administration) in the field of view of MRE and in that of CTE. Recognizing the average 10-year delay in the diagnosis of SpA, both of these imaging modalities could be used as off-label screening tests for diagnosing of SpA, offering an opportunity for an earlier identification of SI in IBD patients according to ASAS classification criteria and EULAR recommendations $[8,36]$. To date, different studies have evaluated the prevalence of SI in patients with IBD using cohorts of subjects undergoing CT or MRI examination; however, the maximum number of patients was about 360 [37-43] and none of these studies reported the prevalence of underreported SI in the CT or MRI reports by radiologists.

The aim of this study was to evaluate the prevalence and the underreporting rate of SI in a large cohort of patients with biopsy-proved Crohn's disease who underwent standard MRE protocols or CTE examinations.

\section{Materials and Methods}

\subsection{Study Design}

This multicenter retrospective study was approved by the institutional review board of our hospitals before the review of any patient material. A study review was undertaken between January 2013 and December 2017 on patients of both sexes with CD who underwent abdominal examinations (CTE or MRE) in 8 different Italian health centers (Siena, Naples, Palermo, Ancona, Siracusa, L'Aquila, Campobasso, Alessandria). Data were extracted from the picture archiving and communicating system (PACS) and pathology databases. Inclusion criteria were as follows: CTE or MRE fulfilled technical eligibility criteria (examination extended to SIJ and slice thickness no more than $2.5 \mathrm{~mm}$ for CT and $6 \mathrm{~mm}$ for MR). Exclusion criteria were CT or MR without or with partial SIJ inclusion in the field of view (FOV) and patients without biopsy-proven CD. Therefore, a total of 894 (429 men, 465 women, age range 15-71 years, mean age 38 years) patients were included in the study. Disease activity for each patient was recorded according to the Crohn's disease activity index (CDAI) [44,45]; in particular, patients were classified as having an "inactive" disease if the CDAI was $\leq 150$ and an "active" disease if the CDAI was $>150$.

\subsection{Biopsy Criteria for Diagnosis of $C D$}

In all eight health centers involved in the study, diagnosis of $C D$ was made on the basis of endoscopic biopsies including the presence of the following histologic features, following Tanaka et al. [46]: segmental crypt atrophy or distortion, segmental mucin depletion, mucin preservation at an ulcer edge or in the crypts with surrounding neutrophils and focal mononuclear cell infiltration.

\subsection{Scanning Protocols}

All the imaging examinations (CTE and MRE) were performed using CT and MR scanners as reported in Table S1. MRE protocols for all health centers are also reported.

\subsection{Image Evaluation}

Each CTE and MRE examination, from which patient personal information has been removed, was analyzed independently by two radiologists from each health center with at least ten and five years' experience respectively in musculoskeletal radiology. Image analysis was performed using a dedicated workstation and the radiologists were permitted to adjust the window settings if necessary. For SIJ analysis, steady state free precession balanced sequences, T2-weighted sequences 
and T1-weighted post-contrast sequences were used for the evaluation of anatomic and structural changes and active inflammation. The readers assessed the presence or absence of SI according to diagnostic imaging criteria following ASAS classifications and EULAR recommendations for SpA [8,36]. In particular, a MRE was considered positive for SI if bone marrow edema, defined as a periarticular hyperintense signal in T2w images, and/or bone marrow contrast enhancement, defined as a hyperintense signal on contrast-enhanced gradient-echo $\mathrm{T} 1 \mathrm{w}$ fat-saturated images, reflecting increased vascularization, were found. In both cases, findings had to be visible on at least two consecutive slices and located in a typical anatomical area (subchondral bone); if no signs of active inflammation were detected, readers looked for subchondral erosions (cortical bony defects at the joint margin indicated by low signal intensity on T1w images and high signal intensity on T2w images if active) or subchondral sclerosis (low intensity for all sequences that did not show signal enhancement after contrast administration), diagnosing SI if a score $\geq 2$ bilaterally or of 3-4 unilaterally, according to New York criteria, was found [47]. CT scans were evaluated following the latter criteria used for MRE (subchondral erosions and sclerosis). As also done by other researchers, a random set of $30 \mathrm{MRI}$ examinations was selected for the assessment of intra- and inter-reader reliability [39]. For intra-reader reliability assessment, these MRE examinations were rescored by an experienced reader with an interval of two months from the original read. For the assessment of inter-reader reliability, images were read by a senior radiologist with 15 years' experience in MRE reading. Before this reading, a learning session utilizing 15 cases was held to help in recognizing findings indicative of sacroiliitis on an MRI and to establish guidelines in the reporting of MRI findings among the readers. Any disagreement was discussed until a consensus was reached. In cases in which SI was diagnosed, the articular involvement was classified as unilateral or bilateral and scored using a simplified SPARCC scoring system [48]. A fixed number of areas per joint were systematically analyzed through multiplanar reconstruction images obtaining a semicoronal section orientated along the long axis of the sacral bone. In particular, in the SIJ, four quadrants were assessed: right upper, left upper, right lower and left lower. Each quadrant was subdivided into iliac and sacral aspects for a total of eight regions (Figure 1). For each quadrant a dichotomous score was assigned based on the presence (score $=1$ ) or absence (score $=0$ ) of the sacroiliac findings reported above. The values for each region were added together with a maximum score of four for each SIJ and eight for each patient.

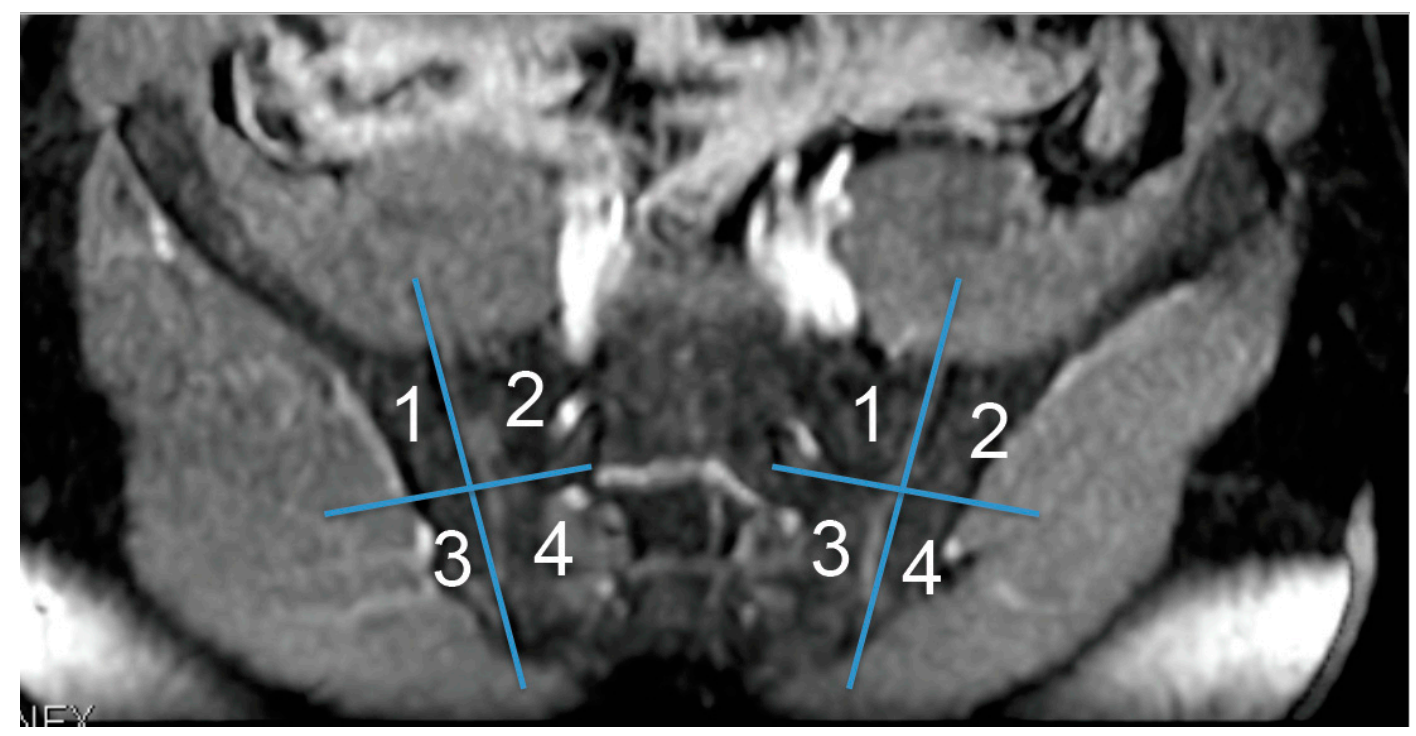

Figure 1. Subdivision of each sacroiliac joint (SIJ) into four quadrants according to a simplified SPARCC scoring system. 


\subsection{Statistical Analysis}

The statistical review of the study was performed by a biomedical statistician. The interobserver agreement was obtained by applying a Kappa test. A descriptive statistical analysis was performed and variables were expressed as percentages. The SIJ scores were expressed as a range and mean \pm standard deviation.

\section{Results}

Interobserver agreement in diagnosing SI through imaging was good $(\mathrm{K}=0.72-0.83)$; the lower agreement was found in detecting erosions in MRE. After consensus, SI was diagnosed in 129 (14.4\%, 54 men and 75 women) out of 894 enrolled patients, 40 in CTE examinations and 89 in MRE examinations. SIJ abnormalities were not mentioned (underreported) in the final radiological reports of 112 patients ( $86 \%$ ), and in particular in 34 CTE and 78 MRE examinations. Fifty (38.7\%) out of 129 patients underwent a subsequent (time interval $18 \pm 6$ months, range 9-25 months) SIJ evaluation through a dedicated MRI protocol, 17 as the result of the CTE or MRE report and the remaining 33 because of symptoms highly suggestive of $S I(n=20)$, primarily low-back pain, or assessment requested by the rheumatologist $(n=13)$; SI was confirmed in the latter exam in all the patients with suggestive findings in CTE or MRE examinations and in 32 symptomatic patients (Figure 2). Among all the 894 patients, $659(73 \%)$ had an "active" disease at the time of the examination whereas the remaining 235 $(27 \%)$ an "inactive" disease and SI was diagnosed in 119 patients of the first group (18\%) and in 10 of the second group (4\%). SI was found to be bilateral in 120 cases and unilateral in the remaining 9 . According to the simplified SPARCC scoring system, the mean score was $2.63 \pm 1.61$ (range 1-8).
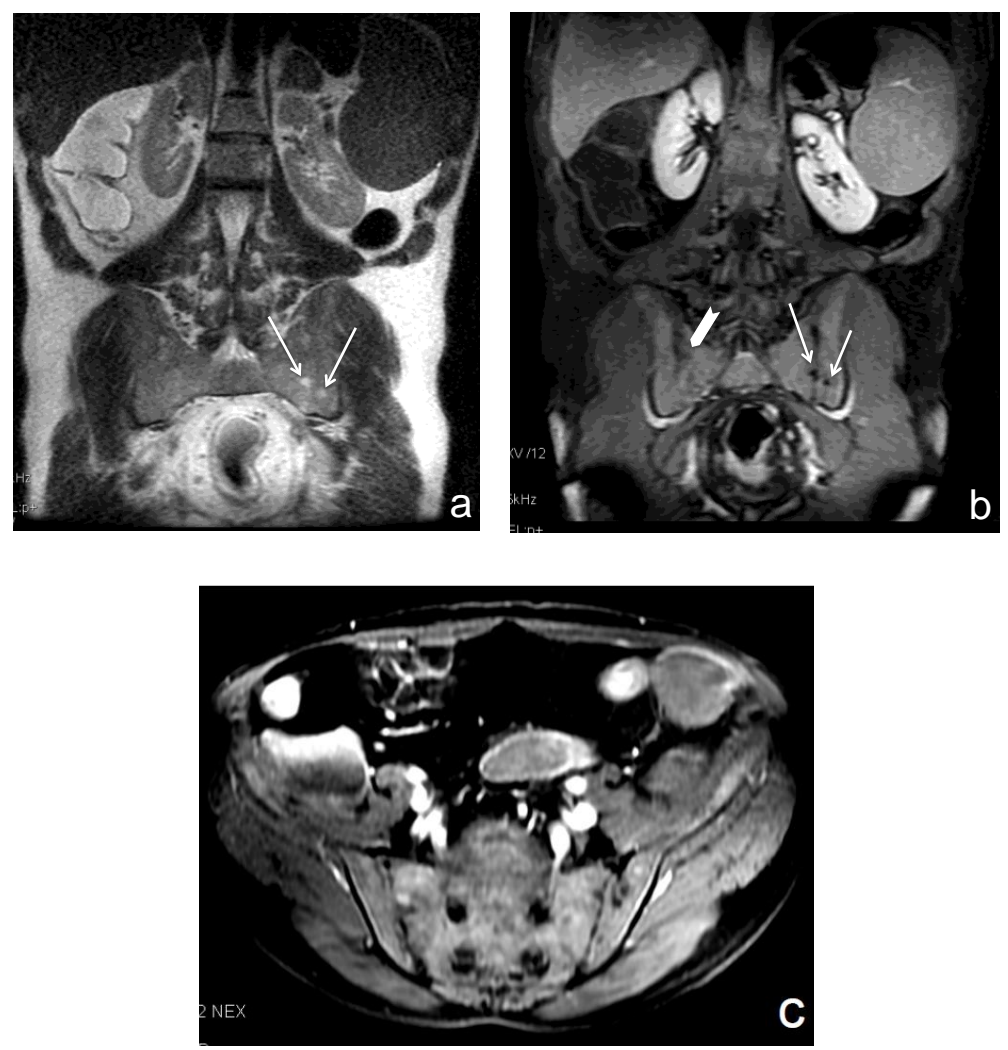

Figure 2. (a-c). SI in a 42 year-old woman with "active" Crohn's disease. A single shot fast spin echo breath hold (SSFSE BH) ASSET T2w sequence in the coronal plane showed subchondral bone marrow edema on both the sacral and iliac aspects of the left SIJ (arrows in (a)) corresponding to erosions (arrows in (b)) on the post-contrast LAVA sequence. Erosions were also detected on the sacral aspect of the right SIJ (arrowhead in (b)). A subsequent dedicated MRI protocol (c) confirmed bilateral SI. 


\section{Discussion}

SI is one of the most common extraintestinal manifestations of spondyloarthropathy, frequently complicating the clinical course of patients with IBD [49-54]. Previous studies that have assessed the prevalence of SI in IBD patients were influenced by the different imaging modalities employed, with results ranging from 1 to $25 \%$ using traditional X-ray, 12 to $45 \%$ using CT and $39 \%$ using MRI [49,52]. Although SI diagnosis is usually based on patient medical history and physical examination, some patients may have mild constitutional symptoms, such as fatigue, loss of appetite or mild fever, which could be awarded to the bowel disease; inflammatory symptoms may also be suppressed by the disease-modifying antirheumatic drugs and corticosteroids, reducing bone marrow edema in SIJ, therefore determining a discordance between musculoskeletal complaints and structural abnormalities, delaying the diagnosis and worsening patient prognosis [43,53,54].

The exact link between CD and SpA has not yet been defined because of the different genetic and immunological factors that may be involved [55-58]. In vitro studies suggest that activated lymphocytes have the capacity to enter the joints adhering to inflamed synovial vessels through multiple adhesion molecules [57]. Peeters et al. found that CARD15 polymorphisms may predispose to sacroiliac involvement in CD patients [55] and Bjarnason et al. found an undefined genetic link between bowel inflammation and SI when assessing first degree relatives of patients with SpA [58]. However, no association has been found between the occurrence and severity of SI and the extension and surgical history of CD in most studies [57].

Conversely, Hwangbo et al. reported an increased prevalence of SI in the presence of perianal and upper gastrointestinal tract diseases, probably as a consequence of more severe immunological responses [42].

The strength of our research is the large cohort of patients with CD enrolled and the prevalence of SI was found to be $12 \%$, which is in line with previous studies [40,42,43,50,51,54]. Interestingly, we found a higher percentage of SI among patients with an "active" disease than among those with an "inactive" disease; this result is in contrast with the data of Leclerc-Jacob et al. and Bandinelli et al., although their study populations were lower ( $n=183$ and $n=81$, respectively), including both CD and UC cases [37,38].

The high rate of SI detected by MRE and CTE, subsequently confirmed by a dedicated MRI protocol, demonstrates the possibility of using both these imaging modalities as screening tools for an earlier diagnosis of SI in patients with $C D$, improving the management of this rheumatological condition. Even if the MRE protocol was not finalized to image the SIJ, neither in scan planes nor in the sequences or scanning parameters, the majority of the exams were judged sufficient to identify SIJ abnormalities.

It should be noted, however, that there was a high percentage of SI underreported by the radiologists that resulted in a significant diagnostic delay. The underreporting phenomenon is widespread in diagnostic imaging, in particular in cross-sectional imaging modalities, because of the high numbers of images, which thus contribute to perceptual error [59-67]. This type of error is related to multiple psychophysiological factors, including level of observation alertness, observer fatigue and the absence of a specific clinical suspicion of SI $[59,63,64]$. In this field the error could also be attributed to mainly cognitive error or mistaken exam interpretation: the radiologists might not have paid enough attention to the SIJ since they were unaware of its frequent inflammatory involvement in IBD patients, or they underestimated or failed to correctly interpret a perceived radiological abnormality because of insufficient experience or knowledge. Thus, expertise in musculoskeletal radiology, and in particular in rheumatologic imaging, is fundamental for a correct interpretation of the exam, especially when abnormalities are not so clear.

Our study had several limitations. Firstly, all data were retrospectively analyzed and we lack any information concerning the biological data (HLA-B27 status) required in order to correctly classify patients with axial SpA according to the ASAS criteria. Secondly, SI was confirmed by a dedicated MRI protocol in a limited percentage of patients so we cannot completely exclude false positive SI 
on MRE due to degenerative changes. Finally, we cannot exclude false negative cases of early SI on CTE since bone marrow edema cannot be detected through this imaging modality. With regard to the latter observation, a mention should be made of the potential use of the dual energy (DE) technique for CT-enterography, considering its benefits in terms of better visualization of affected hypervascular bowel walls in $\mathrm{CD}$ using virtual monoenergetic images at low $\mathrm{keV}$ and of bone marrow edema using material decomposition algorithms [68-71].

In conclusion, this study confirms the feasibility of CTE and MRE for the screening of SI in CD patients, emphasizing at the same time the remarkable issue concerning the underreporting of these finds in radiological practice. However, SI diagnosis should be confirmed by a dedicated MRI protocol and correlated with an appropriate clinical and laboratory evaluation.

Supplementary Materials: The following are available online at http://www.mdpi.com/2036-7422/11/2/8/s1, Table S1. CT and MRI scanners and MRI sequences employed for CTE and MRE in each different centre.

Author Contributions: Conceptualization, M.A.M., F.G., A.M. and L.V.; Data curation, F.G., N.D.M., A.R., A.B., U.P.R., N.M., R.L.S., A.V., G.V., F.B., L.C. and A.M.; Formal analysis, F.G., G.L.R., F.I., A.B., U.P.R. and E.L.P.; Investigation, S.G., G.S., F.B. and B.F.; Methodology, S.G., N.D.M., B.F. and L.V.; Project administration, M.A.M., F.G., G.L.R., M.C., E.L.P., L.V. and L.B.; Resources, A.B., A.V. and A.G.; Software, U.P.R., E.L.P., G.C. and L.C.; Supervision, M.A.M., N.M., A.G. and L.B.; Validation, M.C., N.M. and L.B.; Visualization, G.S., N.M. and G.C.; Writing-original draft, M.A.M. and F.G.; Writing_review \& editing, M.A.M. and F.G. All authors have read and agreed to the published version of the manuscript.

Funding: This research received no external funding.

Conflicts of Interest: The authors declare no conflict of interest.

\section{References}

1. Wills, J.S.; Lobis, I.F.; Denstman, F.J. Crohn disease: State of the art. Radiology 1997, 202, 597-610. [CrossRef]

2. De Vos, M. Joint involvement associated with inflammatory bowel disease. Dig. Dis. 2009, 27, 511-515. [CrossRef]

3. Farraye, F.A.; Odze, R.D.; Eaden, J.; Itzkowitz, S.H.; McCabe, R.P.; Dassopoulos, T.; Lewis, J.D.; Ullman, T.A.; James, T., 3rd; McLeod, R.; et al. AGA medical position statement on the diagnosis and management of colorectal neoplasia in inflammatory bowel disease. Gastroenterology 2010, 138, 738-745. [CrossRef]

4. Akgul, O.; Ozgocmen, S. Classification criteria for spondyloarthropaties. World J. Orthop. 2011, 2, $107-115$. [CrossRef]

5. Guerrini, S.; Giordano, N.; Volterrani, L.; Frediani, B.; Mazzei, M.A. Sonozaki syndrome in the spotlight of imaging. Clin. Rheumatol. 2020. [CrossRef]

6. Guerrini, S.; Bagnacci, G.; Barile, A.; La Paglia, E.; Gentili, F.; Luzzi, L.; Giordano, N.; Fioravanti, A.; Bellisai, F.; Cantarini, L.; et al. Anterior chest wall non-traumatic diseases: A road map for the radiologist. Acta Biomed. 2020, 91, 43-50. [CrossRef]

7. Olivieri, I.; Cantini, F.; Castiglione, F.; Felice, C.; Gionchetti, P.; Orlando, A.; Salvarani, C.; Scarpa, R.; Vecchi, M.; Armuzzi, A. Italian Expert Panel on the management of patients with coexisting spondyloarthritis and inflammatory bowel disease. Autoimmun. Rev. 2014, 13, 822-830. [CrossRef]

8. Mandl, P.; Navarro-Compán, V.; Terslev, L.; Aegerter, P.; van der Heijde, D.; D’Agostino, M.A.; Baraliakos, X.; Pedersen, S.J.; Jurik, A.G.; Naredo, E.; et al. EULAR recommendations for the use of imaging in the diagnosis and management of spondyloarthritis in clinical practice. Ann. Rheum. Dis. 2015, 74, 1327-1339. [CrossRef]

9. Fianyo, E.; Wendling, D.; Poulain, C.; Farrenq, V.; Claudepierre, P. Non-radiographic axial spondyloarthritis: What is it? Clin. Exp. Rheumatol. 2014, 32,1-4.

10. Gentili, F.; Cantarini, L.; Fabbroni, M.; Nigri, A.; Mazzei, F.G.; Frediani, B.; Galeazzi, M.; Volterrani, L.; Mazzei, M.A. Magnetic resonance imaging of the sacroiliac joints in SpA: With or without intravenous contrast media? A preliminary report. Radiol. Med. 2019, 124, 1142-1150. [CrossRef]

11. Marchesoni, A.; D’Angelo, S.; Anzidei, M.; Borlotti, R.; Cantini, F.; Caramella, D.; Carotti, M.; Chimenti, M.; Delle Sedie, A.; Egan, C.; et al. Radiologist-rheumatologist multidisciplinary approach in the management of axial spondyloarthritis: A Delphi consensus statement. Clin. Exp. Rheumatol. 2019, 37, 575-584. 
12. La Paglia, E.; Zawaideh, J.P.; Lucii, G.; Mazzei, M.A. MRI of the axial skeleton: Differentiating non-inflammatory diseases and axial spondyloarthritis: A review of current concepts and applications : Special issue on "musculoskeletal imaging of the inflammatory and degenerative joints: Current status and perspectives". Radiol. Med. 2019, 124, 1151-1166. [CrossRef]

13. Baraliakos, X.; van der Heijde, D.; Braun, J.; Landewé, R.B. OMERACT magnetic resonance imaging initiative on structural and inflammatory lesions in ankylosing spondylitis-report of a special interest group at OMERACT 10 on sacroiliac joint and spine lesions. J. Rheumatol. 2011, 38, 2051-2054. [CrossRef]

14. Bredella, M.A.; Steinbach, L.S.; Morgan, S.; Ward, M.; Davis, J.C. MRI of the sacroiliac joints in patients with moderate to severe ankylosing spondylitis. AJR Am. J. Roentgenol. 2006, 187, 1420-1426. [CrossRef]

15. Hermann, K.G.; Bollow, M. Magnetic resonance imaging of sacroiliitis in patients with spondyloarthritis: Correlation with anatomy and histology. Rofo 2014, 186, 230-237. [CrossRef]

16. Falsetti, P.; Conticini, E.; Mazzei, M.A.; Baldi, C.; Sota, J.; Bardelli, M.; Gentileschi, S.; D'Alessandro, R.; Al Khayyat, S.G.; Acciai, C.; et al. Power and spectral Doppler ultrasound in suspected active sacroiliitis: A comparison with magnetic resonance imaging as gold standard. Rheumatology 2020. [CrossRef]

17. Volterrani, L.; Mazzei, M.A.; Giordano, N.; Nuti, R.; Galeazzi, M.; Fioravanti, A. Magnetic resonance imaging in Tietze's syndrome. Clin. Exp. Rheumatol. 2008, 26, 848-853.

18. Barile, A.; Arrigoni, F.; Bruno, F.; Guglielmi, G.; Zappia, M.; Reginelli, A.; Ruscitti, P.; Cipriani, P.; Giacomelli, R.; Brunese, L.; et al. Computed tomography and MR imaging in rheumatoid arthritis. Radiol. Clin. N. Am. 2017, 55, 997-1007. [CrossRef]

19. Diekhoff, T.; Hermann, K.G.; Greese, J.; Schwenke, C.; Poddubnyy, D.; Hamm, B.; Sieper, J. Comparison of MRI with radiography for detecting structural lesions of the sacroiliac joint using CT as standard of reference: Results from the SIMACT study. Ann. Rheum. Dis. 2017, 76, 1502-1508. [CrossRef]

20. Toussirot, E. New treatment options and emerging drugs for axial spondyloarthritis: Biological and targeted synthetic agents. Exp. Opin. Pharmacother. 2017, 18, 275-282. [CrossRef]

21. Keat, A.; Bennett, A.N.; Gaffney, K.; Marzo-Ortega, H.; Sengupta, R.; Everiss, T. Should axial spondyloarthritis without radiographic changes be treated with anti-TNF agents? Rheumatol. Int. 2017, 37, 327-336. [CrossRef] [PubMed]

22. Marchesoni, A.; Olivieri, I.; Salvarani, C.; Pipitone, N.; D’Angelo, S.; Mathieu, A.; Cauli, A.; Punzi, L.; Ramonda, R.; Scarpa, R.; et al. Recommendations for the use of biologics and other novel drugs in the treatment of psoriatic arthritis: 2017 update from the Italian Society of Rheumatology. Clin. Exp. Rheumatol. 2017, 35, 991-1010. [PubMed]

23. Chitul, A.; Voiosu, A.M.; Marinescu, M.; Caraiola, S.; Nicolau, A.; Badea, G.C.; Pârvu, M.I.; Ionescu, R.A.; Mateescu, B.R.; Voiosu, M.R.; et al. Different effects of anti-TNF-alpha biologic drugs on the small bowel macroscopic inflammation in patients with ankylosing spondylitis. Rom. J. Intern Med. 2017, 55, 44-52. [CrossRef] [PubMed]

24. Fioravanti, A.; Cantarini, L.; Burroni, L.; Mazzei, M.A.; Volterrani, L.; Galeazzi, M. Efficacy of alendronate in the treatment of the SAPHO syndrome. J. Clin. Rheumatol. 2008, 14, 183-184. [CrossRef]

25. Armuzzi, A.; Felice, C.; Lubrano, E.; Cantini, F.; Castiglione, F.; Gionchetti, P.; Orlando, A.; Salvarani, C.; Scarpa, R.; Marchesoni, A.; et al. Multidisciplinary management of patients with coexisting inflammatory bowel disease and spondyloarthritis: A Delphi consensus among Italian experts. Dig. Liver Dis. 2017, 49, 1298-1305. [CrossRef]

26. Bargagli, E.; Bellisai, F.; Mazzei, M.A.; Conticini, E.; Alderighi, L.; Cameli, P.; Biasi, G.; Bergantini, L.; Guerrini, S.; d'Alessandro, M.; et al. Interstitial lung disease associated with psoriatic arthritis: A new disease entity? Intern Emerg. Med. 2020. [CrossRef]

27. Yoon, K.; Chang, K.T.; Lee, H.J. MRI for Crohn's disease: present and future. Biomed. Res Int. 2015, 2015, 786802. [CrossRef]

28. Bruining, D.H.; Bhatnagar, G.; Rimola, J.; Taylor, S.; Zimmermann, E.M.; Fletcher, J.G. CT and MR enterography in Crohn's disease: Current and future applications. Abdom. Imaging. 2015, 40, 965-974. [CrossRef]

29. Grassi, R.; Pinto, A.; Mannelli, L.; Marin, D.; Mazzei, M.A. New Imaging in Gastrointestinal Tract. Gastroenterol. Res. Pract. 2016, 2016, 5785871. [CrossRef]

30. Iacobellis, F.; Berritto, D.; Fleischmann, D.; Gagliardi, G.; Brillantino, A.; Mazzei, M.A.; Grassi, R. CT findings in acute, subacute, and chronic ischemic colitis: Suggestions for diagnosis. Biomed. Res. Int. 2014, 2014, 895248. [CrossRef] 
31. Alabiso, M.E.; Iasiello, F.; Pellino, G.; Iacomino, A.; Roberto, L.; Pinto, A.; Riegler, G.; Selvaggi, F.; Reginelli, A. 3D-EAUS and MRI in the Activity of Anal Fistulas in Crohn's Disease. Gastroenterol. Res. Pract. 2016, 1895694. [CrossRef] [PubMed]

32. Mazzei, M.A.; Guerrini, S.; Cioffi Squitieri, N.; Cagini, L.; Macarini, L.; Coppolino, F.; Melchiore, G.; Volterrani, L. The role of US examination in the management of acute abdomen. Crit. Ultrasound J. 2013, 5. [CrossRef] [PubMed]

33. Mazzei, M.A.; Cioffi Squitieri, N.; Guerrini, S.; Stabile Ianora, A.A.; Cagini, L.; Macarini, L.; Giganti, M.; Volterrani, L. Sigmoid diverticulitis: US findings. Crit. Ultrasound J. 2013, 5 (Suppl. S1), S5. [CrossRef] [PubMed]

34. Mazzei, M.A.; Guerrini, S.; Cioffi Squitieri, N.; Imbriaco, G.; Chieca, R.; Civitelli, S.; Savelli, V.; Mazzei, F.G.; Volterrani, L. Magnetic resonance imaging: Is there a role in clinical management for acute ischemic colitis? World J. Gastroenterol. 2013, 19, 1256-1263. [CrossRef]

35. Mazzei, M.A.; Gentili, F.; Mazzei, F.G.; Grassi, R.; Volterrani, L. Non-occlusive mesenteric ischaemia: CT findings, clinical outcomes and assessment of the diameter of the superior mesenteric artery: Don't forget the reperfusion process! Br. J. Radiol. 2019, 92, 20180736. [CrossRef]

36. Zeidler, H.; Amor, B. The Assessment in Spondyloarthritis International Society (ASAS) classification criteria for peripheral spondyloarthritis and for spondyloarthritis in general: The spondyloarthritis concept in progress. Ann. Rheum. Dis. 2011, 70,1-3. [CrossRef]

37. Leclerc-Jacob, S.; Lux, G.; Rat, A.C.; Laurent, V.; Blum, A.; Chary-Valckenaere, I.; Peyrin-Biroulet, L.; Loeuille, D. The prevalence of inflammatory sacroiliitis assessed on magnetic resonance imaging of inflammatory bowel disease: A retrospective study performed on 186 patients. Aliment Pharmacol. Ther. 2014, 39, 957-962. [CrossRef]

38. Bandinelli, F.; Terenzi, R.; Giovannini, L.; Milla, M.; Genise, S.; Bagnoli, S.; Biagini, S.; Annese, V.; Matucci-Cerinic, M. Occult radiological sacroiliac abnormalities in patients with inflammatory bowel disease who do not present signs or symptoms of axial spondylitis. Clin. Exp. Rheumatol. 2014, 32, 949-952.

39. Gotler, J.; Amitai, M.M.; Lidar, M.; Aharoni, D.; Flusser, G.; Eshed, I. Utilizing MR enterography for detection of sacroiliitis in patients with inflammatory bowel disease. J. Magn. Reason. Imaging. 2015, 42, 121-127. [CrossRef]

40. Chan, J.; Sari, I.; Salonen, D.; Silverberg, M.S.; Haroon, N.; Inman, R.D. Prevalence of Sacroiliitis in Inflammatory Bowel Disease Using a Standardized CT Scoring System. Arthritis Care Res. 2018, 70, 807-810. [CrossRef]

41. McEniff, N.; Eustace, S.; McCarthy, C.; O’Malley, M.; O'Morain, C.A.; Hamilton, S. Asymptomatic sacroiliitis in inflammatory bowel disease. Assessment by computed tomography. Clin. Imaging. 1995, 19, 258-262. [CrossRef]

42. Hwangbo, Y.; Kim, H.J.; Park, J.S.; Ryu, K.N.; Kim, N.H.; Shim, J.; Jang, J.Y.; Dong, S.H.; Kim, B.H.; Chang, Y.W.; et al. Sacroiliitis is common in Crohn's disease patients with perianal or upper gastrointestinal involvement. Gut Liver 2010, 4, 338-344. [CrossRef] [PubMed]

43. Fauny, M.; Cohen, N.; Morizot, C.; Leclerc-Jacob, S.; Wendling, D.; Lux, G.; Laurent, V.; Blum, A.; Netter, P.; Baumann, C.; et al. Low back pain and sacroiliitis on cross-sectional abdominal imaging for axial spondyloarthritis diagnosis in inflammatory Bowel diseases. Inflamm. Intest. Dis. 2020, 5, 124-131. [CrossRef] [PubMed]

44. Sostegni, R.; Daperno, M.; Scaglione, N.; Lavagna, A.; Rocca, R.; Pera, A. Crohn's disease: Monitoring disease activity. Aliment Pharmacol. Ther. 2003, 17, 11-17. [CrossRef] [PubMed]

45. Lo Re, G.; Cappello, M.; Tudisca, C.; Galia, M.; Randazzo, C.; Craxì, A.; Cammà, C.; Giovagnoni, A.; Midiri, M. CT enterography as a powerful tool for the evaluation of inflammatory activity in Crohn's disease: Relationship of CT findings with CDAI and acute-phase reactants. Radiol. Med. 2014, 119, 658-666. [CrossRef]

46. Tanaka, M.; Riddell, R.H.; Saito, H.; Soma, Y.; Hidaka, H.; Kudo, H. Morphologic criteria applicable to biopsy specimens for effective distinction of inflammatory bowel disease from other forms of colitis and of Crohn's disease from ulcerative colitis. Scand. J. Gastroenterol. 1999, 34, 55-67.

47. van der Linden, S.; Valkenburg, H.A.; Cats, A. Evaluation of diagnostic criteria for ankylosing spondylitis. A proposal for modification of the New York criteria. Arthritis Rheum. 1984, 27, 361-368. [CrossRef] 
48. Maksymowych, W.P.; Inman, R.D.; Salonen, D.; Dhillon, S.S.; Williams, M.; Stone, M. Spondyloarthritis research Consortium of Canada magnetic resonance imaging index for assessment of sacroiliac joint inflammation in ankylosing spondylitis. Arthritis Rheum. 2005, 53, 703-709. [CrossRef]

49. Orchard, T.R.; Holt, H.; Bradbury, L.; Hammersma, J.; McNally, E.; Jewell, D.P.; Wordsworth, B.P. The prevalence, clinical features and association of HLA-B27 in sacroiliitis associated with established Crohn's disease. Aliment Pharmacol Ther. 2009, 29, 193-197. [CrossRef]

50. Scott, W.W., Jr.; Fishman, E.K.; Kuhlman, J.E.; Caskey, C.I.; O’Brien, J.J.; Walia, G.S.; Bayless, T.M. Computed tomography evaluation of the sacroiliac joints in Crohn disease. Radiologic/clinical correlation. Skelet. Radiol. 1990, 19, 207-210. [CrossRef]

51. Paparo, F.; Bacigalupo, L.; Garello, I.; Biscaldi, E.; Cimmino, M.A.; Marinaro, E.; Rollandi, G.A. Crohn's disease: Prevalence of intestinal and extraintestinal manifestations detected by computed tomography enterography with water enema. Abdom. Imaging. 2012, 37, 326-337. [CrossRef] [PubMed]

52. Orchard, T.R.; Wordsworth, B.P.; Jewell, D.P. Peripheral arthropathies in inflammatory bowel disease: Their articular distribution and natural history. Gut 1998, 42, 387-391. [CrossRef] [PubMed]

53. Turkcapar, N.; Toruner, M.; Soykan, I.; Aydintug, O.T.; Cetinkaya, H.; Duzgun, N.; Ozden, A.; Duman, M. The prevalence of extraintestinal manifestations and HLA association in patients with inflammatory bowel disease. Rheumatol. Int. 2006, 26, 663-668. [CrossRef] [PubMed]

54. Steer, S.; Jones, H.; Hibbert, J.; Kondeatis, E.; Vaughan, R.; Sanderson, J.; Gibson, T. Low back pain, sacroiliitis, and the relationship with HLA-B27 in Crohn's disease. J. Rheumatol. 2013, 30, 518-522.

55. Peeters, H.; Vander, C.B.; Laukens, D.; Coucke, P.; Marichal, D.; Van Den Berghe, M.; Cuvelier, C.; Remaut, E.; Mielants, H.; De Keyser, F.; et al. Radiological sacroiliitis, a hallmark of spondylitis, is linked with CARD15 gene polymorphisms in patients with Crohn's disease. Ann. Rheum. Dis. 2004, 63, 1131-1134. [CrossRef] [PubMed]

56. Kelly, O.B.; Li, N.; Smith, M.; Chan, J.; Inman, R.D.; Silverberg, M.S. The Prevalence and Clinical Associations of Subclinical Sacroiliitis in Inflammatory Bowel Disease. Inflamm. Bowel Dis. 2019, 25, 1066-1071. [CrossRef] [PubMed]

57. Brakenhoff, L.K.; van der Heijde, D.M.; Hommes, D.W.; Huizinga, T.W.; Fidder, H.H. The joint-gut axis in inflammatory bowel diseases. J. Crohns Colitis. 2010, 4, 257-268. [CrossRef]

58. Bjarnason, I.; Helgason, K.O.; Geirsson, Á.J.; Sigthorsson, G.; Reynisdottir, I.; Gudbjartsson, D.; Einarsdottir, A.S.; Sherwood, R.; Kristjansson, K.; Kjartansson, Ó.; et al. Subclinical intestinal inflammation and sacroiliac changes in relatives of patients with ankylosing spondylitis. Gastroenterology 2003, 125, 1598-1605. [CrossRef]

59. Mazzei, M.A.; Volterrani, L. Errors in multidetector row computed tomography. Radiol. Med. 2015, 120, 785-794. [CrossRef]

60. Casciani, E.; De Vincentiis, C.; Mazzei, M.A.; Masselli, G.; Guerrini, S.; Polettini, E.; Pinto, A.; Gualdi, G. Errors in imaging the pregnant patient with acute abdomen. Abdom. Imaging. 2015, 40, 2112-2126. [CrossRef]

61. Mandato, Y.; Reginelli, A.; Galasso, R.; Iacobellis, F.; Berritto, D.; Cappabianca, S. Errors in the radiological evaluation of the alimentary tract: Part I. Semin. Ultrasound CT MRI 2012, 33, 300-307. [CrossRef] [PubMed]

62. Reginelli, A.; Mandato, Y.; Solazzo, A.; Berritto, D.; Iacobellis, F.; Grassi, R. Errors in the radiological evaluation of the alimentary tract: Part II. Semin. Ultrasound CT MRI 2012, 33, 308-317. [CrossRef] [PubMed]

63. Mazzei, M.A.; Contorni, F.; Gentili, F.; Guerrini, S.; Mazzei, F.G.; Pinto, A.; Cioffi Squitieri, N.; Sisinni, A.G.; Paolucci, V.; Romeo, R.; et al. Incidental and underreported pleural plaques at chest CT: Do not miss them-asbestos exposure still exists. Biomed. Res. Int. 2017, 6797826. [CrossRef] [PubMed]

64. Pinto, A.; Brunese, L.; Pinto, F.; Reali, R.; Daniele, S.; Romano, L. The concept of error and malpractice in radiology. Semin. Ultrasound CT MRI 2012, 33, 275-279. [CrossRef] [PubMed]

65. Bennett, D.; Fossi, A.; Refini, R.M.; Gentili, F.; Luzzi, L.; Voltolini, L.; Paladini, P.; Mazzei, M.A.; Rottoli, P. Posttransplant solid organ malignancies in lung transplant recipients: A single-center experience and review of the literature. Tumori 2016, 102, 574-581. [CrossRef] [PubMed]

66. Mignarri, A.; Gentili, F.; Masia, F.; Genua, A.; Cenciarelli, S.; Brunori, P.; Mazzei, M.A.; Malandrini, A.; Federico, A.; Mazzei, F.G.; et al. Imaging of the thymus in myotonic dystrophy type 1. Neurol. Sci. 2018, 39, 347-351. [CrossRef]

67. Mazzei, M.A.; Sartorelli, P.; Bagnacci, G.; Gentili, F.; Sisinni, A.G.; Fausto, A.; Mazzei, F.G.; Volterrani, L. Occupational Lung Diseases: Underreported Diagnosis in Radiological Practice. Semin Ultrasound CT MRI 2019, 40, 36-50. [CrossRef] 
68. Guler, E.; Unal, N.G.; Hekimsoy, I.; Kose, T.; Harman, M.; Ozutemiz, A.O.; Elmas, N.Z. Dual-energy CT enterography in evaluation of Crohn's disease: The role of virtual monochromatic images. Jpn. J. Radiol. 2020. [CrossRef]

69. Lee, S.M.; Kim, S.H.; Ahn, S.J.; Kang, H.J.; Kang, J.H.; Han, J.K. Virtual monoenergetic dual-layer, dual-energy CT enterography: Optimization of keV settings and its added value for Crohn's disease. Eur. Radiol. 2018, 28, 2525-2534. [CrossRef]

70. Mazzei, M.A.; Gentili, F.; Volterrani, L. Dual-Energy CT Iodine Mapping and 40-keV Monoenergetic Applications in the Diagnosis of Acute Bowel Ischemia: A Necessary Clarification. AJR Am. J. Roentgenol. 2019, 212, W93-W94. [CrossRef]

71. Biondi, M.; Vanzi, E.; De Otto, G.; Banci Buonamici, F.; Belmonte, G.M.; Mazzoni, L.N.; Guasti, A.; Carbone, S.F.; Mazzei, M.A.; La Penna, A.; et al. Water/cortical bone decomposition: A new approach in dual energy CT imaging for bone marrow oedema detection. A feasibility study. Phys. Med. 2016, 32, 1712-1716. [CrossRef] [PubMed]

Publisher's Note: MDPI stays neutral with regard to jurisdictional claims in published maps and institutional affiliations.

(C) 2020 by the authors. Licensee MDPI, Basel, Switzerland. This article is an open access article distributed under the terms and conditions of the Creative Commons Attribution (CC BY) license (http://creativecommons.org/licenses/by/4.0/). 